\title{
Research and Application on the Prediction Method of Pearl Model of High Filling Subgrade Settlement
}

\author{
Xiangxing Kong ${ }^{(凶)}$ \\ The First Highway Survey and Design Institute of China Communications \\ Construction Company Ltd., Xi'an, China \\ 103121153@qq.com
}

\begin{abstract}
According to the development law of high embankment settlement, the Pearl curve model is established. Combined with specific engineering example, the Pearl curve well reflects the change process of high embankment settlement, and the prediction result of the model with the measured settlement value is very accurate and reliable.
\end{abstract}

\section{Introduction}

The construction of expressway in the west, high filling and excavation of roadbed structure are generally occur [1, 2]. After completion construction of high fill embankment subgrade settlement often appear, even cause the destruction of pavement structure engineering accident [3]. In order to ensure the safety of the normal operation of highway, according to the law of development of high filling subgrade settlement observation data and combining site, Pearl model is applied to predict the settlement.

\section{Mechanism of High Filling Subgrade Settlement}

In the early period of construction, just after loading soil is in elastic status. The soil pore water do not exhaust $[4,5]$. Due to the soil of instantaneous shear de-formation, with the increase of load the settlement has approximately linear increase. In the later period of construction, with increasing load, the load imposed in high embankment are also more and more big. The pore water in the foundation soil is gradually discharged, meanwhile excess pore water pressure gradually decreases. So compaction causes more de-formation, and soil in embankment will be in elastic-plastic state. With the continuous development of the plastic zone, settlement rate increases quickly, until the load no longer increases.

After construction, due to the pore water pressure close to disappear completely, the consolidation process is not complete, settlement will continue with the passage of time, but significantly decreased sedimentation rate $[6,7]$. If the time of settlement is infinity, settlement will be at ultimate state, and settlement rate is zero, so the settlement at that time is really the final settlement. In fact, for the highway time takes for 15 years plus filling time. 


\section{The Forecast Model of Pearl Curve}

Pearl curve is sometimes referred as logistic curve, which is based on the American biologists and demographer Raymond Pearl [8]. Because the curve can reflect the growth process of biological, so Pearl curve is widely applied in animal breeding, development of population statistics and analysis of product life cycle and so on. Pearl curve prediction model is expressed as below.

$$
y(t)=\frac{L}{1+a e^{-b t}}
$$

Where: $\mathrm{L}, \mathrm{a}, \mathrm{b}$ are three parameters of the model, in which $\mathrm{a}>0, \mathrm{~b}>0$. Figure 1 is the schematic diagram of typical Pearl curve.

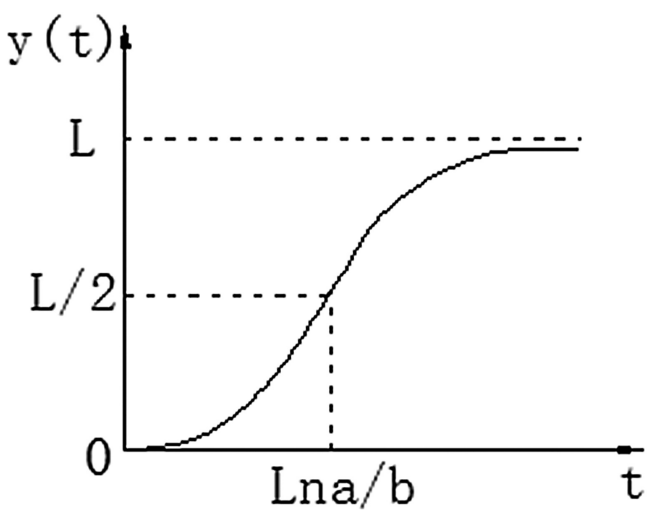

Fig. 1. The carve of Pearl model

Seen from Fig. 1, the change of Pearl curve occurs in the point by the concave. The point is the inflection point of the Pearl curve, which upper and lower halves are around the inflection point symmetry. Also Pearl curve graph is a long strip of S, so it is sometimes referred as $\mathrm{S}$ curve. It describes so regularly, and curve is relatively flat. The description of Pearl curve actually reflects the process of things happening, development, maturity and up to a certain limit. Because of the change of process and Pearl curve settlement of high embankment reflects accurately the process of things development, therefore Pearl curve model can reflect the law of development of high filling subgrade settlement, and is applied to predict the settlement.

\section{Calculation of Parameters}

Using 3 parameters of Pearl curve model method to solve [5] has the following two requirements: 
(1) the settlement data items in the $\mathrm{N}$ time series is a multiple of 3, then the calculation time sequence can be divided into 3 segments, each segment containing items;

(2) before the argument the time interval is equal or the length of time equal to, and which is continuous and interval time series. The time of $\mathrm{T}$ are numbered sequentially starting from $1, \mathrm{t}=1,2,3, \ldots, \mathrm{n}$. According to the requirement, then the number of items in time series is respectively $(i=1,2, \ldots, n)$. The time series is divided into 3 sections: in the first paragraph $t=1,2,3, \ldots$; in the second section, $\mathrm{R}, \mathrm{t}=\mathrm{r}+1, \mathrm{r}=2, \mathrm{r}+3, \ldots$; in the third section $\mathrm{t}=2 \mathrm{r}+1,2 \mathrm{r}+2$, $2 \mathrm{r}+3,2 \mathrm{R}, \ldots, 3 \mathrm{r}$.

Let $\mathrm{S} 1, \mathrm{~S} 2, \mathrm{~S} 3$ respectively for the 3 section numerical the sum, that is

$$
\begin{gathered}
S_{1}=\sum_{t=1}^{r} \frac{1}{y(t)} \\
S_{2}=\sum_{t=r+1}^{2 r} \frac{1}{y(t)} \\
S_{3}=\sum_{t=2 r+1}^{3 r} \frac{1}{y(t)} \\
\frac{1}{y(t)}=\frac{1}{L}+\frac{a e^{-b t}}{L} \\
b=\frac{\ln \frac{\left(s_{1}-s_{2}\right)}{\left(s_{2}-s_{3}\right)}}{r} \\
a=\frac{r}{s_{1}-\frac{\left(s_{1}-s_{2}\right)^{2}}{\left(s_{1}-s_{2}\right)-\left(s_{2}-s_{3}\right)}} \\
\left(s_{1}-s_{2}\right)^{2}\left(1-e^{-b}\right) L
\end{gathered}
$$

So far 3 parameters are calculated by the formula (1), which can be obtained from the Pearl prediction model. Based on the principle and the method of corresponding calculation program is compiled with Matlab. 


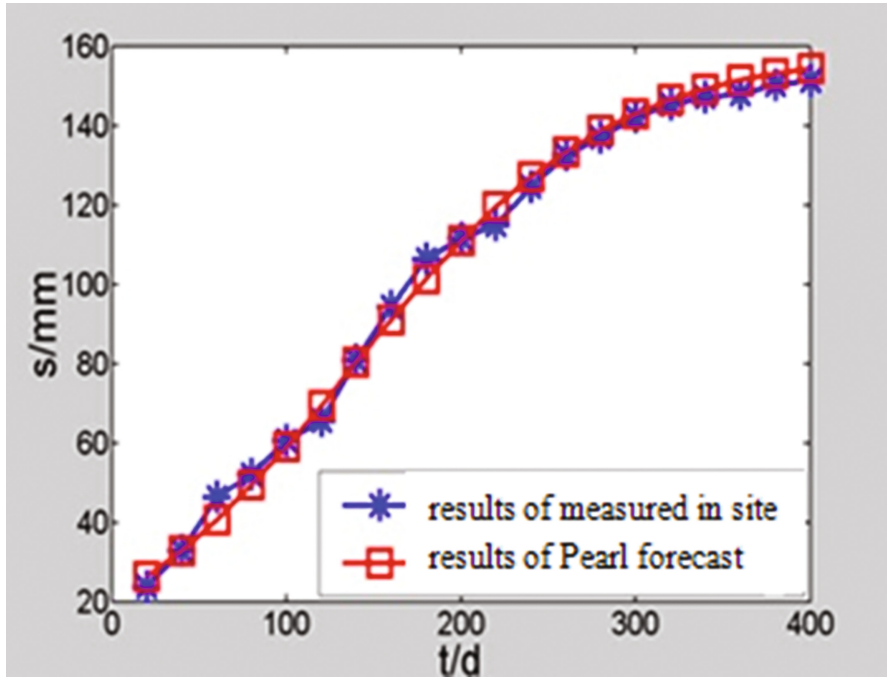

Fig. 2. Results of Pearl and forecasting and measured in K103+380

Table 1. Results of Pearl and forecasting and measured in K103+380

\begin{tabular}{l|l|l|l}
\hline Time $(\mathrm{d})$ & Pearl forecasting $(\mathrm{mm})$ & Measured in site $(\mathrm{mm})$ & Absolute error $(\mathrm{mm})$ \\
\hline 20 & 26.3828 & 23.9 & 2.5 \\
\hline 40 & 32.9468 & 32.9 & 0.0 \\
\hline 60 & 40.6426 & 46.3 & 5.7 \\
\hline 80 & 49.4299 & 52.1 & 2.6 \\
\hline 100 & 59.1656 & 60.6 & 1.5 \\
\hline 120 & 69.5986 & 65.7 & 3.9 \\
\hline 140 & 80.3868 & 80.9 & 0.5 \\
\hline 180 & 91.1385 & 94.4 & 3.3 \\
\hline 200 & 101.4672 & 106.3 & 4.9 \\
\hline 240 & 111.0450 & 111.6 & 0.6 \\
\hline 260 & 119.6399 & 114.9 & 4.7 \\
\hline 280 & 133.4881 & 124.6 & 2.5 \\
\hline 300 & 143.0809 & 132.7 & 0.8 \\
\hline 320 & 146.5447 & 137.0 & 1.8 \\
\hline 340 & 149.2954 & 142.3 & 0.8 \\
\hline 360 & 151.4591 & 145.2 & 1.3 \\
\hline 380 & 153.1483 & 147.1 & 2.2 \\
\hline 400 & 154.4594 & 148.0 & 3.5 \\
\hline & & 150.2 & 2.9 \\
\hline & 151.4 & 3.1 \\
\hline
\end{tabular}


Table 2. Results of Pearl and forecasting and measured in K123+560

\begin{tabular}{l|l|l|l}
\hline Time $(\mathrm{d})$ & Pearl forecasting $(\mathrm{mm})$ & Measured in site $(\mathrm{mm})$ & Absolute error $(\mathrm{mm})$ \\
\hline 20 & 21.48777 & 21.755 & 0.2813 \\
\hline 40 & 29.61882 & 30.305 & 0.7223 \\
\hline 60 & 38.71763 & 43.035 & 4.5446 \\
\hline 80 & 48.45608 & 48.545 & 0.0936 \\
\hline 100 & 58.49492 & 56.62 & 1.9736 \\
\hline 120 & 68.52094 & 61.465 & 7.4273 \\
\hline 140 & 78.27012 & 75.905 & 2.4896 \\
\hline 160 & 87.53908 & 88.73 & 1.2536 \\
\hline 180 & 96.18579 & 100.035 & 4.0518 \\
\hline 200 & 104.1238 & 105.07 & 0.996 \\
\hline 240 & 111.3138 & 108.205 & 3.2724 \\
\hline 260 & 117.7523 & 117.42 & 0.3498 \\
\hline 280 & 123.4631 & 125.115 & 1.7388 \\
\hline 300 & 132.8785 & 129.2 & 0.7498 \\
\hline 320 & 136.6934 & 134.235 & 1.4279 \\
\hline 340 & 139.9921 & 136.99 & 0.3122 \\
\hline 360 & 142.8328 & 138.795 & 1.2601 \\
\hline 380 & 145.2708 & 139.65 & 3.3503 \\
\hline 400 & 147.3569 & 141.74 & 3.7166 \\
\hline & & 142.88 & 4.7125 \\
\hline
\end{tabular}

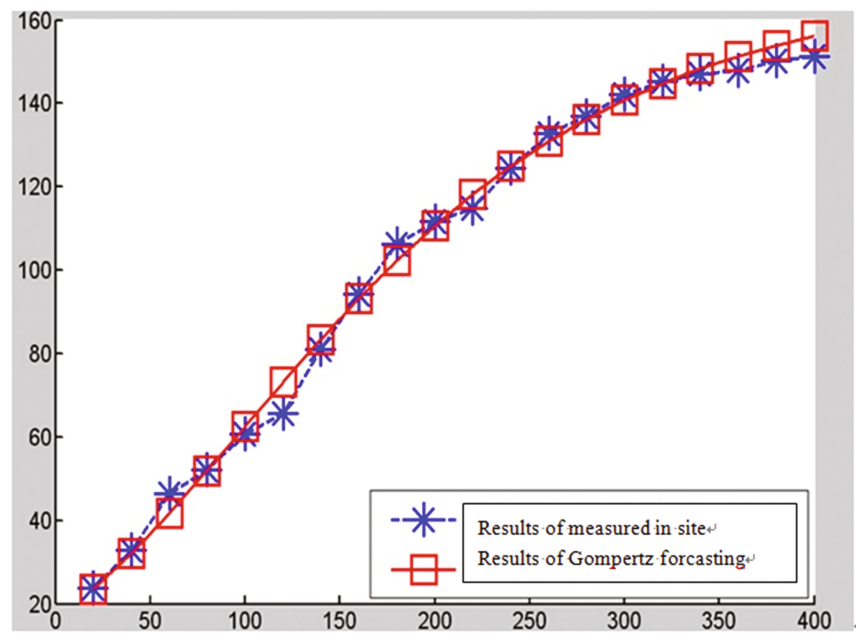

Fig. 3. Results of Pearl and forecasting and measured in K123+560 
Table 3. Parameters of Pearl method

\begin{tabular}{l|l|l}
\hline $\mathrm{L}$ & $\mathrm{a}$ & $\mathrm{b}$ \\
\hline 158.7895 & 6.5942 & 0.2730 \\
\hline
\end{tabular}

\section{Engineering Examples}

Combined with the subgrade settlement observation data in Hunan province Changde-Zhangjiajie expressway, the K103+380, K123+560 are chosen as the case study. The high fill subgrade filler is typical, where is filled with low liquid limit clay and shale, an embankment height is about $13 \mathrm{~m}$.

In Fig. 2, the time-scattered settlement is " $\mathrm{S}$ " shape. The first 12 points (20-240 days) data are selected as samples, Matlab6.5 is used to calculate related parameters of Pearl curve model (as shown in Table 1), then the results of Pearl curve model for settlement prediction of roadbed (as shown in Table 2) are obtained, as well as the sum squared error (prediction precision) 168.13 (Fig. 3 and Table 3).

\section{Conclusion}

In the forecasting of road foundation settlement, different methods can often provide valuable information.

(1) The settlement of high embankment has its own law of development, and Pearl curve is a good reflection of S shape relationship between settlement and time of the whole process of roadbed settlement, mean-while its settlement prediction is accurate and reliable.

(2) Using Pearl curve model in forecasting, in order to obtain good prediction sufficient measured data is basis.

(3) The aging situation also exists in the Pearl prediction model, and with time go recent settlement should be add as the original sample, so that the prediction effect is more better.

\section{References}

1. Xu, J., Cheng, K.K.: Road Engineering. Tongji University Press, Shanghai (1995)

2. Highway Traffic Division: The Highway Engineering Quality Problems Prevent Guide. China Communications Press, Beijing (2002)

3. Gu, X., Qian, H.J., et al.: The Foundation and Foundation. China Architecture Industry Press, Beijing (1993)

4. Zai, J., Mei, K.: Settlement of the whole process of prediction method. Rock Soil Mech. 21 (4), $1322-325$ (2000)

5. Zhao, M., Liu, Y., et al.: The soft soil roadbed settlement development law and its forecasting. J. Cent. South Univ. 35(1), 157-161 (2004) 
6. Pi, D.Y., Sun, Y.: Control and decision of multi model adaptive control. J. Algorithm 11(1), 77-80 (1996)

7. Bates, J.M., Granger, C.W.J.: The combination of forecasts. J. Oper. Res. Soc. 20(4), 451-468 (1969). doi:10.2307/3008764. http://www.jstor.org/stable/3008764

8. Tang, X., Wang, J., et al.: A new combination forecasting method of adaptive fuzzy variable weight. J. Univ. Electron. Sci. Technol. Algorithm 26(3), 289-291 (1997) 